\title{
Um estudo exploratório sobre evocações de estudantes universitários acerca do conceito de limite de uma função
}

\author{
An exlporatory study about universitary students' evocations related to \\ the concept of limit of a function
}

\author{
Maria Alice de Vasconcelos Feio Messias \\ alice.messias@gmail.com
}

João Cláudio Brandemberg

brand@ufpa.br

\begin{abstract}
Resumo
Objetivamos com este trabalho apresentar resultados de uma investigação realizada junto a estudantes universitários acerca do conceito de limite de uma função. Os sujeitos investigados, que cursavam o $3^{\circ}$ e o $4^{\circ}$ semestre de licenciatura em matemática de duas universidades públicas do estado do Pará (Brasil), foram submetidos a duas etapas de investigação de uma pesquisa de mestrado, cujos resultados nos permitiram evidenciar os elementos que compõem suas imagens conceituais relativas ao conceito de limite de uma função. As considerações de Tall e Vinner (1981) e Vinner (1991) sobre imagem conceitual e definição conceitual compuseram a fundamentação teórica de nosso estudo, além de outras pesquisas relacionadas ao processo de ensino e aprendizagem de limite de função, tais como Jordaan (2005), Juter (2006), Nair (2009) e outras. Dentre as imagens conceituais evocadas pelos sujeitos investigados, ressaltamos aquelas voltadas para a ideia de que o valor do limite em determinado ponto não pode ser alcançado, ou seja, $f(x) \neq L$. Optamos por discutir nesse artigo os aspectos relacionados a tal interpretação, mobilizada pelos indivíduos de nossa pesquisa.
\end{abstract}

Palavras-chave: Imagem conceitual evocada, Estudantes universitários, Limite de uma função.

\begin{abstract}
The aim of this paper was to present the results of an investigation that was made with university students about the concept of limit of a function. The subjects, enrolled in third and fourth semester of under graduation in mathematics at two public universities in Pará (Brazil), were submitted to two stages of investigation of a masters' research. Its results allowed us to study the elements that composed their concept image about the concept of limit of a function. Tall \& Vinner (1981) and Vinner (1991) studies concerned to concept image and concept definition composed our study's theoretical framework, besides other researches related to the learning and teaching process of limit of a function, such as Jordaan (2005), Juter (2006), Nair (2009) and others. Among the concept images evoked by the investigated students, we emphasize those related to the idea that the value of the limit at a certain point cannot be achieved, that is, $f(x) \neq L$. We decided to discuss in this article the aspects concerned to that interpretation, which was evoked by the individuals of our research.
\end{abstract}

Keywords: Evoked concept image, University students, Limit of a function. 


\section{Introdução}

Ao longo das últimas décadas do século XX e início do século XXI, diversos estudos e pesquisas em Educação Matemática e em Educação têm mostrado que as dificuldades de aprendizagem em matemática se fazem presentes desde as séries iniciais e se estendem até o segmento superior de ensino. Neste último, percebemos que essas dificuldades se apresentam de maneira expressiva em Cálculo, sobretudo no que concerne à apreensão dos conceitos relacionados à função, limite, continuidade, derivada, integral, dentre outros. Em virtude de essas noções serem objeto de estudo de diversas áreas de conhecimento, verificamos - cada vez mais - o empenho de estudiosos em desenvolver pesquisas com o intuito de oportunizar/viabilizar a compreensão dos entraves inerentes à aprendizagem desses tópicos, bem como a superação dos mesmos.

Diante dessas constatações, direcionamos essa pesquisa para o âmbito do Cálculo e optamos por investigar a problemática da apreensão do conceito de limite de uma função de uma variável real ${ }^{1}$, dada sua importância para o entendimento de outros conceitos. Foi nesse âmbito que a teoria sobre imagem conceitual e definição conceitual (TALL\&VINNER, 1981; VINNER, 1991) foi estabelecida como fundamentação teórica central de nossa pesquisa, cujo objetivo principal consistiu em investigar que elementos compõem a imagem conceitual de estudantes universitários sobre o conceito de limite de função.

Nossa investigação constituiu-se de duas etapas. Primeiramente, aplicamos um questionário contendo questões sobre aspectos conceituais de limite de função para estudantes universitários do curso de licenciatura em matemática de duas universidades públicas no estado do Pará. É importante destacar que esses sujeitos investigados já haviam estudado a disciplina Cálculo I e, portanto, limite de função. A segunda etapa consistiu na realização de entrevistas com alguns dos sujeitos investigados na primeira etapa, a fim de descrever e analisar mais profundamente as imagens conceituais evocadas por eles ao resolverem tarefas cognitivas sobre o objeto de estudo em questão.

A fim de complementar as informações aqui destacadas, explicitamos - no decorrer desse trabalho - a descrição de nosso referencial teórico, das etapas da investigação, bem como alguns dos resultados obtidos, sendo o tópico subsequente dedicado à descrição do suporte teórico estabelecido para essa pesquisa, de maneira a esclarecer sua relação com nosso objeto de estudo.

\footnotetext{
${ }^{1}$ Restringimo-nos à função de uma variável real que, por sua vez, será tratada no decorrer desse artigo somente pelo termo função.
} 


\title{
Fundamentação teórica \& Objeto de estudo
}

Os fundamentos dessa pesquisa estão atrelados às noções de imagem conceitual e definição conceitual (TALL\&VINNER, 1981; VINNER, 1991). Optamos por utilizá-los como fundamentação teórica, pois acreditamos que as atividades propostas, bem como as discussões realizadas nas etapas de investigação de nossa pesquisa possibilitariam a ativação da cela da imagem conceitual dos sujeitos investigados, permitindo-nos analisar suas interpretações relacionadas ao conceito de limite de uma função.

Nesse sentido, atribuímos à imagem conceitual as associações não verbais efetivadas em nossa mente quando em contato com o nome de determinado conceito. Estão incluídas, nesse sentido, suas representações visuais, figuras mentais, impressões e experiências que podem ser traduzidas em formas verbais por meio dessas associações (VINNER, 1991). Dessa maneira,

\begin{abstract}
Devemos utilizar o termo imagem conceitual para descrever a estrutura cognitiva total associada ao conceito, o que inclui todas as figuras mentais, propriedades e processos associados. É construída no decorrer dos anos através de experiências de todos os tipos, diferindo sempre que o indivíduo encontra novos estímulos e maturidade (TALL e VINNER, 1981, p. 152, tradução nossa).
\end{abstract}

Evidenciamos, portanto, que as experiências vivenciadas pelo indivíduo são de extrema importância para a formação de sua imagem conceitual que, por sua vez,

(...) abrange todas as representações de experiências ligadas a um conceito, no qual pode haver diversos conjuntos de representações construídas em contextos diferentes que possivelmente se fundem quando o indivíduo se torna mais matematicamente maduro (JUTER, 2006, p. 17, tradução nossa).

Em virtude da imagem conceitual também ser construída a partir de experiências vivenciadas pelo indivíduo, ela não é necessariamente coerente, podendo conter propriedades e/ou interpretações contraditórias. Ainda assim, segundo Brandemberg (2010), a formação de uma imagem conceitual - por meio do exercício de múltiplas representações de um conceito permite que o sujeito recupere suas impressões e experiências relacionadas a esse conceito e, quem sabe, garanta sua contextualização. Por conseguinte, assumimos que:

(...) adquirir um conceito significa formar uma imagem conceitual para ele. Saber de cor a definição de um conceito não garante seu entendimento. Entender, assim supomos, significa apresentar uma imagem conceitual. Determinado significado deve estar associado às palavras (VINNER, 1991, p. 69, tradução nossa).

A definição conceitual consiste nas definições, memorizadas ou auto - construídas por um indivíduo. Tall e Vinner (1981) atribuem a essa noção toda forma em palavras utilizada para 
especificar um conceito. Sempre que a definição de um conceito é dada ou construída pelo indivíduo, esta sofrerá variações de tempo em tempo. Para Cornu (1983), a definição conceitual é composta por:

(...) frases apreendidas mecanicamente, mais ou menos ligadas a um conceito; pode ser uma reconstrução, uma reformulação pessoal de uma definição matemática; é também o conjunto de palavras que empregamos para explicar o conceito. Essa fraseologia é própria ao indivíduo: ela não coincide sempre com a definição formal do conceito, ou seja, com a definição comumente admitida pela comunidade matemática (p. 66, tradução nossa).

Sobre a relação entre imagem e definição conceitual, concordamos com Meyer (2003) no sentido de que ambas "pontuam a diferença existente entre os conceitos matemáticos quando formalmente definidos e os processos cognitivos pelos quais eles são concebidos, ou seja, é estabelecida uma distinção entre a matemática como uma atividade mental e a matemática como um sistema formal” (p. 6). No que se refere à formação de um conceito, Brandemberg (2010) aponta que:

(...) uma pessoa pode criar uma ou múltiplas representações mentais para um mesmo conceito matemático, podemos inferir que é apoiado nessas representações que se torna possível a ampliação concreta do número de representações simbólicas ligadas a um determinado conceito, posto que cada representação mental estará associada a seu modelo de representação simbólica (p. 115)

A título de exemplificação dos estudos de Tall e Vinner (1981) e Vinner (1991), apresentamos no tópico a seguir ilustrações de imagens conceituais que se fizeram presentes nas mobilizações de estudantes investigados em outras pesquisas sobre o conceito de limite de função.

\section{Exemplificando imagens conceituais de limite de uma função}

O estudo realizado por Tall e Vinner (1981) objetivou levantar aspectos sobre as imagens conceituais de estudantes relacionadas aos conceitos de limite de uma sequência $\lim _{n \rightarrow \infty} S_{n}$, limite de uma função $\lim _{n \rightarrow a} f(x)$ e continuidade de uma função $f: D \rightarrow I R$. Em se tratando do conceito de limite de função, os autores apontam que:

(...) assim como o limite de sequência, o limite de uma função é normalmente considerado um processo dinâmico, em que $x$ se aproxima de $a$, provocando a aproximação de $f(x)$ em relação à $c$. Novamente os estudantes consideram $f(x) \neq c$ como parte da imagem conceitual (TALL\&VINNER, 1981, p. 159, tradução nossa). 
Em um questionário aplicado para estudantes do primeiro ano do curso de matemática, os autores solicitaram que os indivíduos explicassem o que significava a expressão $\lim _{x \rightarrow 1} \frac{x^{3}-1}{x-1}=3$ e escrevessem uma definição para $\lim _{x \rightarrow a} f(x)=c$, caso soubessem. Dentre as observações de Tall e Vinner (1981) sobre as imagens conceituais evocadas pelos sujeitos investigados, destacamos:

- A maioria deles apresentou uma noção dinâmica sobre a definição de limite, por exemplo, "o valor que $f(x)$ se aproxima quando os valores de $x$ chegam perto de $a$ é c” (TALL \& VINNER, 1981, p. 160, tradução nossa);

- Os autores evidenciaram que a utilização de expressões como "se aproxima", "chega perto", "tende a" levam a ideia de que $f(x) \neq c$, sendo esse um fator de conflito potencial;

Tall e Vinner (1981) concluíram que:

(...) a dificuldade em formar uma imagem conceitual apropriada e os efeitos coercivos de uma imagem conceitual inapropriada que apresenta conflitos em potencial, pode atingir seriamente o desenvolvimento de uma teoria formal na mente do indivíduo (p.167, tradução nossa).

Jordaan (2005) realizou uma pesquisa com o intuito de identificar os erros conceituais apresentados por estudantes de engenharia elétrica da Tshwane University of Technology (África do Sul) sobre o conceito de limite de função, buscando - mediante o estudo desenvolvido - verificar como os sujeitos investigados entendiam a noção de limite, que tipo de erros eles apresentavam nesse aspecto e como eles relacionavam continuidade e descontinuidade de uma função em um ponto com a existência do limite naquele ponto.

Sua pesquisa foi dividida em duas etapas. A primeira etapa consistiu na aplicação de um questionário, cujo foco era somente o conceito de limite. Ou seja, aspectos concernentes às manipulações algébricas utilizadas para calcular limites não foram considerados. Os objetivos estabelecidos para essa etapa foram os seguintes: determinar o entendimento dos estudantes sobre limites, continuidade e descontinuidade de função em um ponto, descobrir como os estudantes entendem a (não) existência do limite em um ponto de continuidade/descontinuidade e determinar como os estudantes lidam com um gráfico de função que apresenta descontinuidade em um ponto.

$\mathrm{Na}$ segunda etapa, foi realizada uma entrevista com seis dos 42 sujeitos investigados na primeira etapa da pesquisa. Os objetivos estabelecidos para essa etapa são semelhantes 
àqueles da etapa anterior, isto é, avaliar a compreensão gráfica e simbólica sobre limites, determinar o entendimento dos estudantes sobre continuidade/descontinuidade de uma função em determinado ponto e como o mesmo influencia na compreensão sobre a (não) existência do limite neste ponto.

Os resultados obtidos por Jordaan (2005) permitiram-na enunciar observações quanto à natureza do conceito de limite, quanto à relação entre continuidade de funções e limites e outras, conforme observamos a seguir:

\begin{tabular}{|c|c|c|}
\hline \multicolumn{3}{|c|}{ Quadro 1: Imagens conceituais evocadas - JORDAAN (2005) } \\
\hline Natureza do conceito de limite & Relação entre continuidade e limites & Outras observações \\
\hline $\begin{array}{l}\text { Os estudantes veem limite como } \\
\text { sendo uma fronteira; } \\
\text { Os estudantes veem limite como } \\
\text { sendo inalcançável; }\end{array}$ & $\begin{array}{l}\text { Os estudantes acreditam que a função } \\
\text { deve necessariamente estar definida } \\
\text { em um ponto para que a mesma } \\
\text { apresente limite naquele ponto. Uma } \\
\text { função que não esteja definida em um } \\
\text { ponto não apresenta limite; }\end{array}$ & $\begin{array}{l}\text { Os estudantes acreditam que } \\
\text { o limite é igual o valor da } \\
\text { função no ponto. Ou seja, } \\
\lim _{x \rightarrow a} f(x)=f(a) \text {. }\end{array}$ \\
\hline $\begin{array}{l}\text { Os estudantes veem limite como } \\
\text { sendo uma aproximação; } \\
\text { Os estudantes tem a impressão de } \\
\text { que a função sempre apresentará } \\
\text { limite em determinado ponto; }\end{array}$ & $\begin{array}{l}\text { Os estudantes ponderam que quando } \\
\text { uma função tem um limite, então } \\
\text { deve ser contínua naquele ponto; }\end{array}$ & \\
\hline $\begin{array}{l}\text { Os estudantes visualizam limite } \\
\text { como um processo dinâmico e não } \\
\text { como um objeto estático. }\end{array}$ & & \\
\hline
\end{tabular}

Jordaan (2005) recomendou a realização de outras pesquisas no sentido de investigar, dentre outras situações, os processos cognitivos na aquisição da ideia de limite por parte dos estudantes, o papel de uma abordagem centrada na aprendizagem de limites, o efeito da utilização de tecnologias na aprendizagem de limites, bem como o desenvolvimento de estratégias de ensino que assegurem uma real compreensão desse conceito.

Juter (2006) apresentou a sinopse de uma pesquisa realizada com estudantes universitários na Suécia sobre o desenvolvimento conceitual de limite de função. Mediante a investigação realizada, a pesquisadora objetivou identificar como as percepções dos sujeitos investigados sobre limites se desenvolvem, se essas percepções podem estar relacionadas ao desenvolvimento histórico desse conceito, como os estudantes resolvem tarefas envolvendo 
limites, bem como evidenciar qual a relação entre as atitudes dos sujeitos investigados e seus respectivos desempenhos em atividades envolvendo limite de função.

Sua pesquisa foi constituída por dois estudos. Participaram do primeiro estudo 43 estudantes universitários. Os sujeitos investigados preencheram três questionários, cujos principais objetivos foram:

- Obter informações sobre a educação prévia dos estudantes, suas atitudes e conhecimento sobre limites;

- Verificar como os estudantes interpretavam suas situações de aprendizagem;

- Verificar o quanto os estudantes poderiam explicar os cálculos efetuados, bem como o quanto separavam funções de limite de funções em suas imagens conceituais;

- Verificar se os sujeitos investigados poderiam explicar seus conhecimentos sobre limites em situações não tradicionais;

No segundo estudo, participaram 112 estudantes universitários. Os sujeitos investigados preencheram três questionários. Em seguida, foram selecionados 34 estudantes para participarem de duas entrevistas. O objetivo foi descrever e analisar mais profundamente as situações de aprendizagens dos participantes da pesquisa.

Juter (2006) obteve resultados que a permitiram evidenciar os seguintes resultados:

- Os sujeitos investigados apresentaram dificuldades em entender características específicas da noção de limite, tais como decidir se a função pode alcançar o valor do limite e/ou determinar o que os componentes da definição representam;

- Os estudantes apresentaram dificuldade em calcular limites, como por exemplo, o $\lim _{x \rightarrow 1} \frac{x^{2}-1}{x-1}$

- Os estudantes apresentaram confusões entre limite de função e função;

- Os sujeitos da pesquisa não conseguiram estabelecer/entender o significado dos quantificadores envolvidos na definição de limite;

- As imagens conceituais dos indivíduos acerca do conceito de limite se mostraram incoerentes com sua definição; 
Por fim, a autora observou que a definição formal de limite de função não foi integrada às imagens conceituais dos estudantes e, portanto, não estava disponível como ferramenta durante a realização das tarefas matemáticas. Além disso, "muitas desconexões no desenvolvimento da aprendizagem foram detectadas no estudo, por exemplo, entre as percepções intuitiva e formal, procedimental e estática, finita e infinita (...)” (JUTER, 2006, p. 38, tradução nossa).

Nair (1009) realizou uma investigação acerca da imagem conceitual de estudantes de Cálculo no que concerne aos conceitos de função racional, assíntotas, limites e continuidade e as possíveis conexões entre os mesmos. Dentre seus objetivos com a pesquisa, a autora almejou verificar que conexões entre os conceitos de assíntotas, continuidade e limite de funções racionais os sujeitos investigados apresentavam, bem como os efeitos de um experimento de ensino realizado no decorrer da pesquisa na compreensão desses conceitos.

A pesquisa constituiu-se de uma entrevista, realizada com 19 estudantes, um experimento de ensino conduzido pela autora e uma segunda entrevista, esses últimos realizados com sete estudantes. As intenções de Nair (2009) com as entrevistas foram, dentre outras, verificar que noção os sujeitos investigados apresentavam sobre limites, continuidade e assíntotas, bem como que conexões (caso existissem) os estudantes estabeleciam entre esses conceitos. A partir das imagens conceituais identificadas nas entrevistas, a autora desenvolveu os planos de aula que foram usados nos episódios de ensino, cujo foco foi como os esquemas conceituais dos estudantes mudavam no decorrer de interações matemáticas entre eles e/ou a pesquisadora.

As imagens conceituais dos sujeitos investigados sobre limites e continuidade fizeram Nair (2009) verificar as dificuldades relacionadas à utilização da terminologia correta, interpretação de limites a partir do gráfico da função, cálculo de limites e a relação entre limites com o comportamento de assíntotas de funções. Nesse aspecto a autora evidenciou que:

- Ao invés dos estudantes estabelecerem que " $x$ se aproxima de $a, f(x)$ se aproxima de $L "$, trocavam/confundiam o papel de $x$ e $y$ e $x$ e $f(x)$

- Os sujeitos investigados acreditavam que o limite não existe em determinado ponto se a função não estiver definida naquele ponto; 
- Os estudantes acreditam que o $\lim _{x \rightarrow a} f(x)$ deve ser necessariamente igual a $f(a)$. Caso contrário, o limite não existirá.

- Os estudantes apresentaram dificuldade em calcular limites infinitos e limites no infinito;

- Quando se deparavam com indeterminações, os sujeitos investigados afirmavam que o limite da função não existia;

- As dificuldades associadas ao conceito de limite de função residem no fato dos estudantes "simplesmente focarem no processo, o processo de encontrar limites utilizando procedimentos de substituição direta e simplificação (...)" (NAIR, 2009, p. 114, tradução nossa);

- Alguns estudantes acreditavam que para uma função ser contínua, basta seus limites laterais serem iguais;

- Os resultados indicaram que os estudantes tinham a impressão de que limites são pontos alcançados pela função;

Finalmente, Nair (2009) sugere que mais experimentos sejam desenvolvidos para examinar a compreensão conceitual dos estudantes sobre assíntotas, limites e continuidade. Além disso, recomenda o ensino de cálculo em um ambiente em que as assíntotas sejam introduzidas junto com o conceito de limite para que, posteriormente, seja avaliado o aperfeiçoamento da compreensão desses conceitos, por meio dessa estratégia de ensino.

As pesquisas descritas nesse tópico nos permitiu verificar que a dificuldade na apreensão desse conceito se faz presente na vida acadêmica de grande parte dos estudantes que participam de um curso de Cálculo. Percebemos então a necessidade de concentrar nosso estudo no processo de ensino - aprendizagem do conceito de limite de função, dada sua importância para o estudo de conceitos adjacentes e, objetivando fundamentar nossa pesquisa, baseamo-nos na teoria e definições sobre imagem e definição conceitual, desenvolvidas por Tall e Vinner (1981) e Vinner (1991) e suas relações com o nosso objeto de estudo (limite de função). A fim de viabilizar o entendimento do leitor acerca da relação entre nossos objetivos para com essa pesquisa e o referencial teórico estabelecido, elaboramos o quadro a seguir: 


\begin{tabular}{|c|c|c|}
\hline Referencial teórico & Objetivo(s) do referencial teórico & Relação com nossos objetivos \\
\hline Tall e Vinner (1981) & $\begin{array}{l}\text { Levantar aspectos concernentes à } \\
\text { Imagem Conceitual de estudantes } \\
\text { acerca de três noções: limite de uma } \\
\text { sequência } \lim _{n \rightarrow \infty} S_{n} \text {, limite de uma } \\
\text { função } \lim _{n \rightarrow a} f(x) \text { e continuidade de } \\
\text { uma função } f: D \rightarrow I R\end{array}$ & $\begin{array}{l}\text { Assim como no estudo de Tall e Vinner } \\
\text { (1981), objetivamos estudar aspectos } \\
\text { concernentes às noções de imagem e } \\
\text { definição conceitual. Em contrapartida, } \\
\text { nosso objeto de estudo restringe-se ao } \\
\text { conceito de limite de função. }\end{array}$ \\
\hline Jordaan (2005) & $\begin{array}{l}\text { Identificar os erros conceituais } \\
\text { apresentados por estudantes sobre o } \\
\text { conceito de limite de função; } \\
\\
\text { Verificar como os sujeitos investigados } \\
\text { entendem a noção de limite e que tipo } \\
\text { de erros eles apresentam nesse aspecto, } \\
\text { além de evidenciar como eles } \\
\text { relacionam continuidader e } \\
\text { descontinuidade de uma função em um } \\
\text { ponto com a existência do limite } \\
\text { naquele ponto; }\end{array}$ & $\begin{array}{l}\text { Os objetivos traçados por Jordaan (2005) } \\
\text { encontram-se em conformidade com os } \\
\text { que delimitamos para nossa pesquisa, } \\
\text { sobretudo em relação à investigação das } \\
\text { imagens conceituais evocadas pelos } \\
\text { sujeitos investigados no que concerne à } \\
\text { relação entre continuidade e a existência } \\
\text { do limite, sendo esse referencial de suma } \\
\text { importância para a análise dos resultados } \\
\text { obtidos em nosso estudo. }\end{array}$ \\
\hline Juter (2006) & 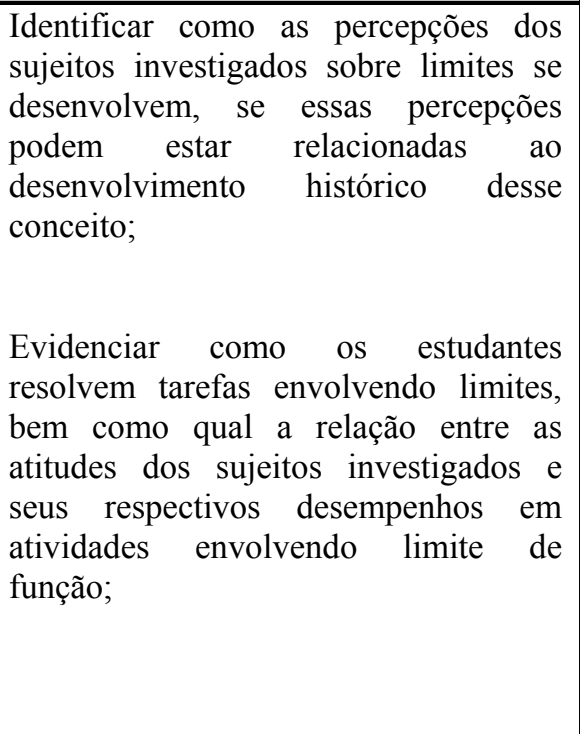 & $\begin{array}{l}\text { Nossos objetivos se aproximam aos de } \\
\text { Juter (2006) no sentido de que assim } \\
\text { como a autora, almejamos verificar junto } \\
\text { aos sujeitos investigados suas percepções } \\
\text { acerca do conceito de limite a partir de } \\
\text { tarefas e entrevistas que envolvam tal } \\
\text { conceito. Pretendemos evidenciar - da } \\
\text { mesma maneira que Juter (2006) - } \\
\text { imagens conceituais que caracterizem os } \\
\text { conhecimentos dos estudantes no que } \\
\text { concerne ao conceito de limite de função, } \\
\text { bem como a relação entre imagem } \\
\text { conceitual, definição conceitual pessoal } \\
\text { e definição conceitual formal. } \\
\text { Ressaltamos que as considerações de } \\
\text { Juter (2006) foram de extrema relevância } \\
\text { para a análise dos resultados obtidos em } \\
\text { nossa pesquisa. }\end{array}$ \\
\hline Nair (2009) & $\begin{array}{l}\text { Verificar que conexões entre os } \\
\text { conceitos de assíntotas, continuidade e } \\
\text { limite de funções racionais os sujeitos } \\
\text { investigados apresentavam; bem como } \\
\text { os efeitos do experimento de ensino } \\
\text { realizado no decorrer da pesquisa na } \\
\text { compreensão desses conceitos. }\end{array}$ & $\begin{array}{l}\text { Apesar de nossa investigação não } \\
\text { promover o estudo dos mesmos } \\
\text { conceitos explorados por Nair (2009), } \\
\text { suas considerações sobre as imagens } \\
\text { conceituais de estudantes acerca de } \\
\text { limite de funções e continuidades foram } \\
\text { fundamentais para a construção dos } \\
\text { instrumentos utilizados para obtenção de } \\
\text { dados, bem como para a análise das } \\
\text { imagens conceituais evocadas acerca da } \\
\text { relação limite x continuidade } \\
\text { apresentadas pelos indivíduos } \\
\text { investigados em nossa pesquisa. }\end{array}$ \\
\hline
\end{tabular}


Ressaltamos que o referencial teórico estabelecido foi fundamental para o desenvolvimento de nosso estudo, tendo em vista que complementou nossas perspectivas em relação aos objetivos previamente estabelecidos, e subsidiou tanto na construção dos instrumentos de coleta de dados quanto na análise das imagens conceituais evocadas pelos sujeitos investigados em nossa pesquisa.

\section{Pesquisa realizada \& Imagens conceituais evocacas}

Discutiremos nesse artigo alguns resultados provenientes da segunda etapa de investigação de nossa pesquisa de mestrado, na qual foram realizadas entrevistas com 2 dos 25 sujeitos investigados acerca da temática de discussão intitulada "O valor do limite é alcançado?". Objetivamos com esse tema de discussão (TD) investigar as imagens conceituais evocadas pelos sujeitos no que se refere à ideia de que a função se aproxima de determinado valor sem, no entanto, alcançá-lo. Ou seja, $f(x) \neq L$ (TALL \& VINNER, 1981; JORDAAN, 2005; JUTER, 2006).

Ressaltamos que as sessões de entrevistas nortearam-se em um roteiro pré-estabelecido, conforme quadro 3 (a seguir):

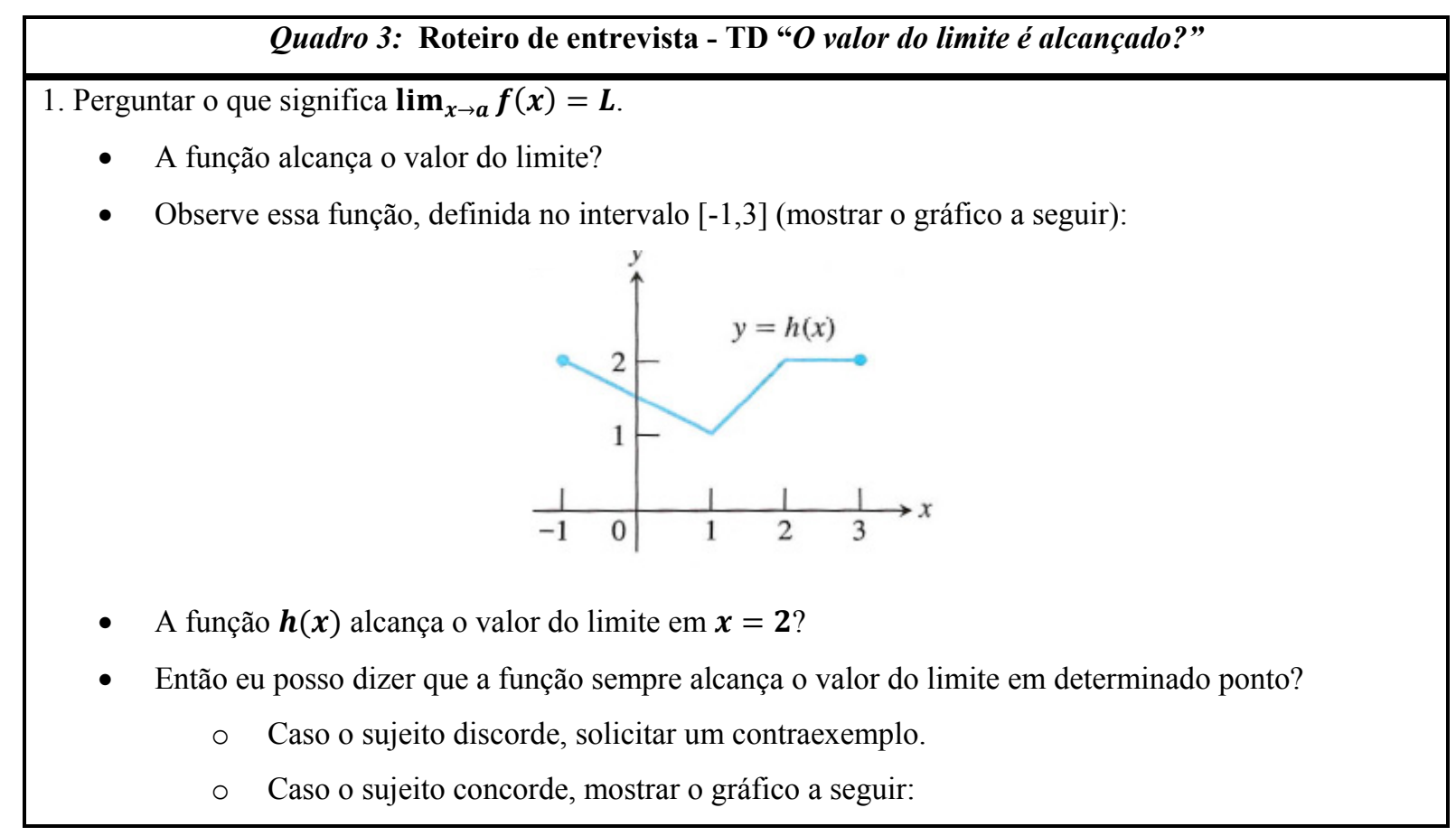




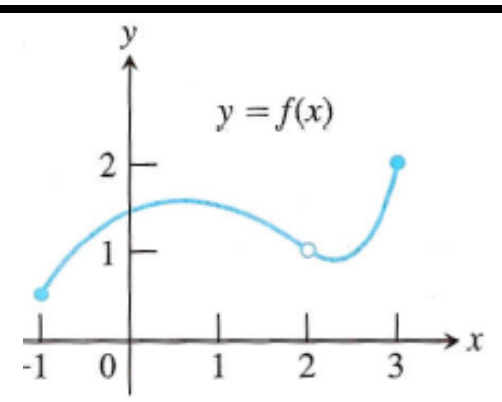

- $\quad$ A função, nesse caso, alcança o valor do limite em $x=2$ ?

○ Em caso de resposta afirmativa, pedir que o sujeito justifique sua afirmação;

- Em caso de resposta negativa, perguntar:

- Então, para a função alcançar o valor do limite em um ponto 'p' qualquer, ela deve estar definida naquele ponto?

- E se ela não estiver definida naquele ponto?

Você poderia escrever uma definição para $\lim _{x \rightarrow a} f(x)=\boldsymbol{L}$ e, mais uma vez, dizer o que significa?

$\mathrm{O}$ roteiro de entrevista destacado no quadro 3 foi elaborado com o intuito de investigar as imagens conceituais evocadas dos sujeitos acerca da possibilidade do valor do limite poder ou não ser alcançado. Optamos por esse tema em virtude de evidenciarmos, em nossas investigações anteriores, evocações que mobilizaram uma ideia de aproximação em relação a determinado valor sem alcançá-lo, isto é, $f(x) \neq L$ e, a fim de analisá-las mais profundamente, incluímos nesse TD gráficos de uma função contínua e de uma descontínua para verificar se - da mesma maneira que Juter (2006) observou - evidenciaríamos junto aos sujeitos a relação, mais uma vez, entre a (des) continuidade de funções com o fato de o limite ser ou não alcançado.

Além disso, ressaltamos que decidimos perguntar aos indivíduos da pesquisa o significado de $\lim _{x \rightarrow a} f(x)=L$, no sentido de verificar a imagem conceitual e definição conceitual pessoal dos mesmos, suas relações com a definição conceitual formal de limite de função e, sobretudo, se a evocação de um limite inalcançável faria parte das imagens conceituais desses indivíduos.

Destacamos a seguir a descrição de alguns trechos dos episódios ${ }^{2}$, analisando-os de acordo com os pontos de conformidade e/ou não conformidade com o referencial teórico previamente estabelecido. Ressaltamos que apesar de termos elaborado um roteiro para o TD, realizamos

\footnotetext{
${ }^{2}$ Organizamos a análise dos resultados em episódios. Cada episódio corresponde à entrevista com um dos sujeitos. A análise apresentada nesse artigo foi composta, portanto, de 2 episódios.
} 
outros questionamentos que pudessem complementar nossas análises, conforme as particularidades de cada sujeito investigado.

\section{Episódio 1}

O primeiro episódio apresenta a entrevista realizada com o sujeito S02 sobre suas percepções acerca da possibilidade de uma função poder ou não alcançar o valor do limite em determinado ponto, haja vista que esse sujeito evocou na $1^{\mathrm{a}}$ etapa da pesquisa imagens conceituais características desse tema de discussão.

Ao perguntarmos ao sujeito S02 o que significava $\lim _{x \rightarrow a} f(x)=L$, evidenciamos a evocação de uma imagem conceitual voltada para a ideia de aproximação, conforme destacamos a seguir.

E: Primeiro, eu gostaria de saber o que significa o $\lim _{x \rightarrow a} f(x)=$ L. O que isso significa pra ti?

S02: É o valor que tende a L no ponto A, não que chegue em $L$, mas próximo de $L$.

E: Essa proximidade depende de que exatamente?

S02: Até onde eu sei, você aproxima tanto pela direita quanto pela esquerda de tal modo que eles quase se encontram, mas não chegam naquele ponto.

As respostas do sujeito S02 evocam as expressões ditas dinâmicas que são inerentes a uma imagem conceitual pautada na percepção de que o limite é um valor do qual nos aproximamos, porém, não atingimos ou ultrapassamos, estando esses aspectos mobilizados em acordo com as observações de Tall e Vinner (1981), Jordaan (2005) e Juter (2006), ou seja, a ideia de que $f(x) \neq L$ fez parte da imagem conceitual desse sujeito.

No que concerne ao fato da função alcançar ou não o valor do limite em determinado ponto, evidenciamos que S02 considera a existência do limite nesse ponto. Ou seja, se o limite existir, então ele pode ser alcançado, fazendo-nos concluir que, nesse momento, a definição conceitual pessoal apresentada anteriormente pelo sujeito entra em conflito com a imagem conceitual evocada por ele (ver o trecho da entrevista a seguir).

E: Então, eu vou te mostrar um exemplo e outra função (segundo gráfico do roteiro). Nesse caso, o que eu posso falar do limite dessa função no ponto 2? 
S02: No ponto 2..., ele existe. Tanto que existe uma aproximação tanto pela direita quanto pela esquerda só que ela não é contínua porque no ponto $x=2$ ela é um intervalo aberto.

E: Certo, e isso influencia ou não no fato da função alcançar ou não o limite?

S02: Não. Também não.

E: Então eu posso dizer que a função alcança o limite?

S02: A função alcança o limite, mas ela não é contínua.

E: Então, para a função alcançar o limite ela pode ou não estar definida neste ponto?

S02: Sim.

Consideramos, portanto, que para esse sujeito investigado o fato da função alcançar ou não o limite constituiu-se como um fator de conflito potencial (VINNER, 1991) e, por isso, acreditamos ser necessário que tal aspecto seja discutido em sala de aula, de maneira a viabilizar a formação da imagem conceitual dos estudantes, tornando-a coerente não só com a definição conceitual pessoal dos mesmos, mas também com a definição conceitual formal de limite de função.

Por fim, ressaltamos que S02 definiu limite a partir da evocação da ideia de aproximação, conforme podemos verificar tanto no início da entrevista quanto no momento em que, mais uma vez, solicitamos que ele definisse limite de função:

E: E, depois dessa conversa que nós tivemos você poderia escrever uma definição para limite e explicar, mais uma vez, o que significa.

S02: Bem, existe uma função né, para todo x que ela tende à a, existe um limite L que ela tem que se aproximar lateralmente, tanto pela direita quanto pela esquerda. Essa aproximação é o limite L.

A análise do episódio 1 nos possibilitou evidenciar a dificuldade de S02 em relação ao entendimento do conceito de limite de função, dada a incoerência presente na relação entre as imagens conceituais evocadas por ele e a definição conceitual formal de limite de função, fato que se fez presente também na primeira etapa de nossa investigação e que se estendeu aos demais episódios de nossa pesquisa de mestrado. 


\section{Episódio 2}

O segundo episódio refere-se à entrevista realizada com o sujeito S14 sobre o TD em questão, ou seja, sobre o fato da função poder ou não alcançar o valor do limite em determinado ponto. Esse sujeito também evocou, na $1^{\text {a }}$ etapa da pesquisa, imagens conceituais características desse tema de discussão. Mais uma vez, lembramos que realizamos outros questionamentos que pudessem complementar nossas análises.

O sujeito S14 evocou, inicialmente, a ideia de que $f(x) \neq L$ (TALL \& VINER, 1981; JORDAAN, 2005; JUTER, 2006). Isso pode ser evidenciado na definição conceitual pessoal de limite de função apresentada na entrevista (ver transcrição, a seguir).

E: Então, a primeira coisa que eu queria te perguntar é o que significa pra você $\lim _{x \rightarrow a} f(x)=L$.

S14: É... olhando assim para um gráfico, seria_o valor que a função teria no ponto, se o gráfico dela passasse por esse ponto. Basicamente isso.

Quanto à questão de a função alcançar ou não o limite, S14 se remete a duas situações: a existência do limite e a continuidade da função. Isto é, se o limite existe em determinado ponto e a função for contínua nesse ponto, então ele pode ser alcançado, conforme destacamos no seguinte trecho da entrevista realizada.

E: ok, tu podes, então, me dar um exemplo de uma função que não alcança o valor do limite em determinado ponto?

S14: ok (pausa)... essa função aqui, formada por $f(x)=\left\{\begin{array}{c}x, \text { se } x \leq 1 \\ 3-x, \text { se } x>1\end{array}\right.$, vamos supor essa função (desenha o gráfico)... no ponto 1, essa função não vai ser contínua no ponto 1, ai agora eu quero calcular o limite dela quando x tender a 1, no ponto onde ela não é contínua. Se eu for calcular esse limite, no caso como a função tem duas sentenças, então o que que a gente vai fazer, calcular os limites laterais. Os limites pela esquerda e pela direita, né? Então se eu for calcular o limite pela esquerda, o que eu vou encontrar? Vou encontrar 1. Se eu for encontrar o limite pela direita, eu vou encontrar 2. Os limites laterais são diferentes, então o limite da função não vai existir, então como é que eu vou alcançar? Então o limite não existe.

E: Tá. Se o limite existe, então a função alcança?

S14: Sim. Peraí, deixa eu pensar um pouquinho (risos). Vamos analisar, se o limite da função existe e a função alcança o valor do limite é porque a função tem que ser contínua pra 
poder alcançar o limite no ponto dado. É, acredito que sim, se ela for contínua, então ela alcança o valor do limite.

Nesse sentido, a imagem conceitual do sujeito S14 encontra-se em acordo com as observações de Juter (2006). Isso porque, o sujeito destacou que a função pode, algumas vezes, alcançar o valor do limite (nesse caso, se ela for contínua), sendo que evidenciamos o conflito entre essas evocações e a definição conceitual pessoal destacada por ele anteriormente (na qual mobilizou a ideia de que $f(x) \neq L$ ).

Observamos, ainda que S14, ao estabelecer uma definição conceitual para limite de função, apresentou conflitos relacionados ao fato da existência do limite em determinado ponto estar vinculada ao domínio da função, caracterizando-se para esse sujeito, um fator de conflito potencial (VINNER, 1991), haja vista que, em outros momentos, suas imagens conceituais desvinculam a existência do limite em relação à continuidade e, consequentemente, ao fato da função estar definida no ponto estudado (ver transcrição, a seguir).

E: então, depois dessas perguntas que eu te fiz, dessa discussão que a gente teve, eu queria que tu escrevesses uma definição para limite de uma função e dizer, mais uma vez o que ela significa. Como tu definirias limite então? Fique à vontade.

S14: Intuitivamente, o limite ele é um valor que a função tem ou teria no ponto $P$, dependendo da continuidade; se ela for contínua no $P$, então o limite dessa função em $p$ vai ser a própria $f(P)$. Se ela não for, e se o limite existir, seria o valor que essa função teria, digamos assim, no ponto P. Agora, formalmente, envolvendo épsilon e o delta, esse eu já tenho um pouco de dificuldade (...)

E: Certo. Mas então assim, você coloca, seja uma função $f$ e um ponto $P$ no domínio de $f$, então P tem que pertencer ao domínio de f?

S14: P... sim.

E: Certo. Aí, continuando.... você colocou aqui esse $f(x)$ é a função e esse $f(P)$ é o limite?

S14: Sim... se a função for contínua.

E: Então, para melhor ajustar aqui, quando você coloca $|f(x)-f(P)|<\varepsilon$ me dá a entender que $f(P)$ é o limite entendeu? Então, como você poderia escrever isso aqui melhor?

S14: Tirando do módulo? (pensou um pouco)... é o limite aqui... é porque eu tô me confundindo, mas aqui é o limite, vai ser $f(P)$ se for contínua. 
Assim como em etapas anteriores de nossa investigação, os resultados obtidos no episódio 2 encontram em conformidade com os estudos de Tall e Vinner (1981), no sentido de que as imagens conceituais evocadas pelo indivíduo influenciam na construção de uma definição conceitual pessoal que difere da definição conceitual formal de limite de função, principalmente no que concerne à sua relação com a noção de continuidade (COTTRILL et al, 1996; JORDAAN, 2005; JUTER, 2006; NAIR, 2009).

\section{Considerações finais}

Com esse artigo nos propusemos a apresentar parte dos resultados de uma pesquisa de mestrado, cujo objetivo central foi investigar os elementos que compõem a imagem conceitual de estudantes universitários sobre limite de função, inferidos a partir da evocação de aspectos relacionados a esse conceito.

No caso dos resultados apresentados nesse trabalho, elucidamos que os mesmos foram obtidos a partir de entrevistas com 2 dos sujeitos investigados na etapa anterior, de maneira a complementar nossas análises concernentes à temática intitulada " $O$ limite pode ser alcançado?”, em que objetivamos investigar a percepções desses indivíduos acerca da possibilidade do limite por ou não ser alcançado. Nesse sentido, observamos que as imagens conceituais dos sujeitos participantes do TD em questão pautaram-se, sobretudo, nas duas importantes evocações a seguir:

[E1] A ideia de limite como sendo um valor a ser alcançado pela função por meio de constantes aproximações. Desse modo, o limite em determinado ponto é tido como um valor que deve coincidir com o valor da função nesse ponto, ou seja, $\lim _{x \rightarrow p} f(x)=f(p)$;

[E2] O limite é um valor, do qual a função se aproxima tanto quanto queiramos sem, no entanto, alcançá-lo. Isto é, $f(x) \neq L$;

Ressaltamos que as evocações E1 e E2 assemelham-se aos resultados obtidos por Tall e Vinner (1981), Jordaan (2005) e Juter (2006). Isso porque, os resultados permitiram-nos evidenciar que, de fato, os estudantes relacionavam o conceito de limite de função com interpretações estáticas e/ou dinâmicas que, em alguns momentos, constituíram-se como fatores de conflito potencial (VINNER, 1991), principalmente no que concerne à possibilidade do valor do limite poder ou não ser alcançado. 
Essas evocações também nos permitiram evidenciar que algumas das imagens conceituais evocadas pelos sujeitos investigados não se fizeram coerentes com a definição conceitual, fato que os influenciou a construir uma definição conceitual pessoal diferente da definição conceitual formal de limite de função.

Reiteramos que os resultados obtidos em nossa investigação foram de grande relevância no sentido de nos permitir verificar alguns dos conflitos que permeiam as imagens conceituais dos estudantes em relação ao conceito de limite de função. Nesse sentido, esperamos que as discussões levantadas neste trabalho sirvam de subsídio para o desenvolvimento de pesquisas futuras que busquem viabilizar o processo de ensino e aprendizagem das noções de limite de função por meio de atividades que auxiliem na formação de imagens conceituais consistentes e, sobretudo, coerentes com sua definição conceitual formal.

\section{Referências}

BARTO, M. C. Um olhar sobre as ideias matemáticas em um curso de cálculo: a produção de significados para continuidade. Dissertação de mestrado (Educação Matemática). PUC (SP), 2004.

BRANDEMBERG, J. C. Uma análise histórico-epistemológica do conceito de grupo. Tese de doutorado (Educação Matemática). UFRN (Natal), 2009.

Uma análise histórico-epistemológica do conceito de grupo. São Paulo: Editora Livraria da Física, 2010.

CORNU, B. Apprentissage de la notion de limite - conceptions et obstacles. Tese de doutorado (matemática). Université Scientifique et Medicale de Grenoble, 1983.

. Limits. In: TALL, David (Ed.) Advanced Mathematical Thinking. Kluwer publications, 1991.

COTRILL et al. Understanding the limit concept: beginning with a coordinate process schema. In: Journal of mathematical behavior, vol. 15, 1996, p. $167-192$.

GRAY, E. M; TALL, D. Success and failure in mathematics: The flexible meaning of symbols as process and concept. In: Mathematics teaching, n. 142, p. 6 - 10, 1993.

JORDAAN, T. Misconceptions of the limit concept in a mathematics course for engineering students. Dissertação de mestrado (Educação Matemática). University of South Africa, 2005.

JUTER, K. Limits of functions: University students' concept development. Tese de doutorado (Educação Matemática). Lulea University of Technology, 2006.

NAIR, G. S. College students' concept image of asymptotes, limits and continuity of rational functions. Tese de doutorado (Filosofia). Ohio State University, 2010. 
OLIMPIO, A. Primeiro ano num curso de matemática: a definição de função e a dualidade local/global em conceitos de cálculo. In: Boletim de Educação Matemática. Rio Claro (SP), Ano 20, n. 28, pp. 39 a 67, 2007.

RODRÍGUEZ, M. Consideraciones didácticas para la enseñanza del límite funcional. In: Memorias Del $10^{\circ}$ Simposio de Educación Matemática. Chivilcoy - Buenos Aires Argentina, p. $92-98,2009$.

SIERPINSKA, A. Obstacles epistemologiques relatifs a la notion de limite. In: Recherches en didactique des mathématique, vol. 6, n.1, p. 6-67, 1985.

TALL, D. Concept image and concept definition. In: Senior Secondary Mathematics Education, p. 37 - 41, 1988.

. The psychology of advanced mathematical thinking. In:TALL, David (Ed.) Advanced Mathematical Thinking. Kluwer publications, 1991.

. The transition to advanced mathematical thinking: functions, limits, infinity and proof. In: Handook of research on mathematics teaching and learning, p. 495 - 511, 1992.

TALL, D; VINNER, S. Concept image and concept definition with particular reference to limits and continuity. In: Educational Studies in Mathematics, n. 12, p. 151 - 169, 1981.

THOMAS, G.B. Cálculo. São Paulo: Addison Wesley, vol 1, 2002.

VINNER, S. The role of definitions in teaching and learning. In: Advanced Mathematical Thinking (Ed. David Tall). Kluwer publications, 1991.

ZUCHI, I. A abordagem do conceito de limite via sequência didática: do ambiente lápis e papel ao ambiente computacional. Tese de doutorado (Engenharia de Produção). UFSC, 2005. 